\title{
Kırım Kongo Kanamalı Ateşinde Hemogram Parametrelerinin Tanısal Değeri
}

\section{Diagnostic Value of Hemogram Parameters in Crimean-Congo Hemorrhagic Fever}

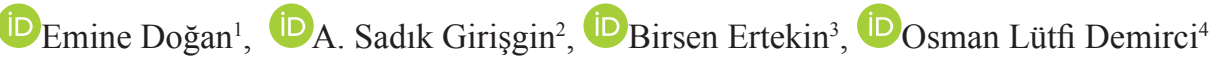

${ }^{1}$ Başkent University, Medical Faculty, Emergency Department, Konya, Turkey.

${ }^{2}$ Necmettin Erbakan University Meram Faculty of Medicine, Emergency Department, Konya, Turkey.

${ }^{3}$ Beyhekim State Hospital, Emergency Department, Konya,Turkey

${ }^{4}$ Keçiören Education Research Hospital, Emergency Department, Ankara, Turkey

\section{$\ddot{O} \mathrm{z}$}

Giriş: Ülkemizde son yıllarda Kırım Kongo kanamalı ateşi (KKKA), yüksek mortalitesi nedeni ile dikkat çekmektedir.

Amaç: KKKA'da meydana gelen inflamatuar sürecin, tam kan parametreleri üzerine olan etkisini araştırmaktır.

Gereç ve Yöntem:01.01.2010 - 31.12.2011 tarihleri arasında acil servisimize, kene ile temas şikayetiyle başvuran toplam 5260 hasta retrospektif olarak incelendi. Klinik olarak şüpheli 80 vakaya yapılan serolojik inceleme sonunda KKKA tanısı için 40 hastada pozitif ve 40 hastada negatif sonuç bulundu. Sağlıklı gönüllü 40 kişiden kontrol grubu oluşturuldu. Hastalardan başvuru sırasında alınan tüm hemogram parametreleri, hasta ve kontrol grubu ile ayrı ayrı karşılaştırıldı.

Bulgular: KKKA pozitif ve negatif olan hasta grubu, kontrol grubu ile kiyaslandığında; lökosit, nötrofil, red cell distribution width (RDW), mean platelet volume (MPV), nötrofil-lenfosit oranı (NLR) ve trombosit-lenfosit oranı (PLR) değerleri sadece KKKA pozitif olan grupta anlamlı tespit edildi. Oysa lenfosit ve platelet değerleri her iki grupta da anlamlı bulunmuştur $(\mathrm{p} \leq 0.01)$.

Sonuç: Bu çalışmada elde edilen verilere göre özellikle acil servislerde ucuz, kolay ve yaygın olarak kullanılabilecek bu tam kan parametreleri KKKA tanısında klinisyenlere yardımcı olabilir.

Anahtar Kelimeler: kırım kongo kanamalı ateşi, nötrofil lenfosit oranı, platelet-lenfosit oranı, ortalama platelet hacmi, kırmızı kan hücreleri dağılım genişliği

\begin{abstract}
Introduction: Crimean-Kongo hemorrhagic fever (CKHF) has pulled attention in recent years due to its high mortality rate.
\end{abstract}

Objective: To investigate the effect of the inflammatory process in Crimean-Kongo hemorrhagic fever on the complete blood count parameters.

Material and Methods: A total of 5260 patients who had presented to theemergency room of our hospital due to tick contact between 01 January 2010 and 31 December 2011 were analyzed retrospectively. Serological examination yielded 40 positive and 40 negative results for 80 cases with suspicion of CKHF. Forty healthy volunteers constituted the control group. All of the complete blood cell count parameters that were examined on admission were compared separately with the patient and the control group.

Results: When CKHF positive and negative patient groups were compared with the control group, the neutrophil, red cell distribution width (RDW), mean platelet volume (MPV), neutrophil/lymphocyte ratio (NLR) and the platelet/lymphocyte ratio (PLR) values were found to be significant in the CKHF-positive group only. However, the lymphocyte and the platelet values were found to be significant in both groups ( $\mathrm{p} \leq 0.01)$.

Conclusion: The results of the present study suggest that complete blood count parameters, which are inexpensive, easy and widely used, may be useful for the diagnosis of Crimean-Kongo hemorrhagic fever in the emergency room.

Keywords: Crimean-Kongo hemorrhagic fever, neutrophil/lymphocyte ratio, platelet/lymphocyte ratio, mean platelet volume, red cell distribution width

Yazışma Adresi: Emine Doğan, Başkent University, Medical Faculty, Emergency Department, Konya, Turkey

E-Posta: dredogan42@hotmail.com

Alınma Tarihi : 18.05.2019/ Kabul Tarihi : 03.09.2020 / Yayımlanma Tarihi : 25/06/2021 
edilmiştir. Kontrol grubu olarak, sağlıklı gönüllülerden oluşan toplam 40 (23 kadın - 17 erkek) kişi alındı. Acil servise başvuru sırasında

Kırım-Kongo kanamalı ateşi (KKKA), ülkemizde bazı bölgelerde endemik olarak görülen, ateş ve kanamalarla seyreden sıklıkla kenelerden bulaşan, mortal seyredebilen zoonotik bir enfeksiyondur. Günümüzde Asya, Afrika ve Güney-Doğu Avrupa'da ülkemizin de içinde bulunduğu 30'dan fazla ülkede halen görülmeye devam etmektedir (1). Türkiye'de KKKA olguları Sivas, Çorum, Tokat, Yozgat, Amasya, Gümüşhane, Trabzon ve Erzurum illerinde endemik, diğer illerde ise sporadik olarak görülmektedir. 2002 yılından itibaren, günümüze kadar 10.000'in üzerinde vaka bildirimi yapılmıştır. Hastalık; inkübasyan dönemi, prehemorajik, hemorajik ve konvelesan dönem olmak üzere dört ana dönemde tanımlanmıştır. Semptomları, ateş, baş ağrısı, miyalji, ishal, bulantı ve kusmadır. Laboratuvar bulgularında; lökopeni, trombositopeni, AST, ALT, LDH, ve CK yüksekliği görülür (2).

KKKA'nin patogenezi tam olarak aydınlatılamamıştır. Endotel hücreleri, bağışıklık yanıt, viral yük ve pıhtılaşma kaskadı hastalık patogenezinde önemli rol oynar. Hemorajik ateş virüslerinin bilinen en önemli özelliği, virüsün konak hücrelerine saldırarak immün cevabın devre dışı bırakılmasıdır (3). Virüsün replikasyonu ile birlikte vasküler sistem ve lenfoid dokuların regülasyonunda bozulma nedeni ile doku ve organ hasarı oluşur (4). Virüsün etkisi ile salınan proinflamatuar sitokinler damar endoteli, hedef hücreler ve dokularda inflamatuar immün yanıta neden olur (5).

Günümüzde yapılan birçok çalışma, yüksek nötrofil-lenfosit oranı (NLR), trombosit-lenfosit oranı (PLR), Mean Platelet Volume (MPV) ve Red cell distribution width (RDW) değerlerinin inflamasyonda arttığını göstermektedir. Ayrıca bu parametrelerin hepsine kolay ve ucuz bir şekilde tam kan testinde rutin olarak bakılabilmektedir (6-9). Bu yüzden çalışmadaki amacımız KKKA tanılı hastalarda inflamatuvar sürecin, lökosit, nötrofil, lenfosit, platelet, PLR, NLR, MPV ve RDW düzeyleri üzerine olan etkisini araştırmaktır.

\section{Materyal ve Metod}

\section{Hastalar ve süreç}

$\mathrm{Bu}$ çalışmada, 01.01.2010 - 31.12.2011 tarihleri arasında acil servisimize kene ile temas şikayetiyle başvuran toplam 5260 olgu retrospektif olarak incelenmiştir. Aynı şekilde hastaların yaş, cinsiyet, başvuru anındaki Lökosit, Nötrofil, Lenfosit, Platelet, Hemoglobin, RDW, MPV değerleri ve klinik sonuçlarına hastane kayıt sisteminden ulaşılmıştır. NLR ve PLR değerleri hemogram analizinden elde edilen nötrofil, lenfosit ve trombosit sayıları kullanılarak hesaplandı. KKKA açısından şüpheli vakalar; kene ile temas hikayesine ek olarak; ateş, kas ağrıs1, bulantı, kusma ve kanama şikayeti olan hastalardan oluşturuldu. Antienflamatuar, antioksidan, immunsupresiv, antikoagulan, platelet agregasyon inhibitörü kullanan hastalar ile akut- kronik inflamatuvar, hematolojik, romatolojik, otoimmun, kardiyovaskuler, pulmoner hastalığı olanlar, hipertansiyon, diyabet, pankreatit, sepsis, kanserler, travmalar, gebeler, sigara içenler, karaciğer ve böbrek yetmezliği olan hastalar çalışma dışı bırakılmıştır. Çalışmaya 80 KKKA şüpheli vaka alındı. Kesin vakalar ise şüpheli vakalardan, serolojik inceleme için Refik Saydam Sağlık Merkezi'ne (KKKA referans merkezi/ viroloji laboratuvar1/ Ankara) gönderilen kan örneklerinde KKKA polimeraz zincir reaksiyonu (PCR) $(+)$ veya KKKA Ig M (+) olanlardan elde edildi. Bu serolojik inceleme sonuçları 40 hastada (20 bayan- 20 erkek) pozitif iken 40 hastada (14 bayan- 26 erkek) negatif olarak tespit hastalardan alınan tüm $\mathrm{CBC}$ parametreleri hasta ve kontrol grubu ile ayrı ayrı istatistiksel olarak karşılaştırıldı. Çalışma üniversite Yerel Etik Kurulu tarafından onaylanmış ve Helsinki Deklerasyonu'nun etik ilkelerine uygun şekilde yürütülmüştür.

\section{Biyokimyasal analiz}

WBC, RDW, MPV, hemoglobin, nötrofil, lenfosit, platelet düzeyleri hemotoloji cihazı (Sysmex-XT 2000İ, Istanbul, Turkey) ile çalışılmıştır.

\section{İstatistiksel Analiz}

İstatistiksel analizler için SPSS 13.0 (SPSS Inc, Chicago, Illinois, USA) yazılımı kullanılmıştır. Kantitatif değişkenler ortalama \pm standart sapma ve kategorik değişkenler de olgu sayısı (\%) olarak ifade edildi. İki grubun normal ve anormal dağılımları 'Bonferroni düzeltmeli Mann Whitney U testi' kullanılarak değerlendirildi. Gruplar arasındaki farklılıkların karşılaştırılmasında, kantitatif değişkenler için bağımsız-t testi, kategorik değişkenler için ki-kare testi kullanıldı. İstatistiksel anlamlılık \%95 güven ile 0.05 'in altında bir $\mathrm{p}$ değeriydi (Bonferroni düzeltmesinde $\mathrm{p}<0,01$ ).

\section{Bulgular}

KKKA pozitif ve negatif olan hastaların ortalama yaşları sırasıyla 48 ve 30 iken kontrol grubunun yaş ortalaması 48 idi. KKKA pozitif ve negatif olan hastaların erkek sayısı sırasıyla 20 (\%50) ve $26(65 \%)$ iken kontrol grubunun erkek sayıs 17 (42.5\%) idi. Hastaların sadece 5 (\%12.5)'i ex olmuştur. KKKA pozitif ve negatif olan hasta grubu, kontrol grubu ile kıyaslandığında; lökosit, rdw, nötrofil, MPV, NLR ve PLR değerleri sadece KKKA pozitif olan grupta istatistiksel olarak anlamlı tespit edildi. Oysa lenfosit ve platelet değerleri her iki grupta da anlamlı bulunmuştur $(\mathrm{p} \leq 0.01)$ (Tablo1).

Tablo1. KKKA pozitif, negatif ve kontrol grubu arasındaki değerlendirilen parametrelerin karşılaştırılması

\begin{tabular}{lllll}
\hline Ortalama & $\begin{array}{l}\text { KKKA } \\
\text { POZiTiF } \\
(\mathbf{n}: 40)\end{array}$ & $\begin{array}{l}\text { KKKA } \\
\text { NEGATiF } \\
(\mathbf{n}: 40)\end{array}$ & $\begin{array}{l}\text { KONTROL } \\
(\mathbf{n}: 40)\end{array}$ & P value * \\
\hline Yaş & 48 & 30 & 48 & \\
\hline Cinsiyet & $\begin{array}{l}\text { Men:20 } \\
(50 \%)\end{array}$ & $\begin{array}{l}\text { Men:26 } \\
(65 \%)\end{array}$ & $\begin{array}{l}\text { Men:17 } \\
(42.5 \%)\end{array}$ & \\
& $\begin{array}{l}\text { Female:20 } \\
(50 \%)\end{array}$ & $\begin{array}{l}\text { Female:14 } \\
(35 \%)\end{array}$ & $\begin{array}{l}\text { Female: } 23 \\
(57.5 \%)\end{array}$ & \\
\hline WBC & $4,01 \pm 0.4$ & $7,97 \pm 0.8$ & $7,69 \pm 0.2$ & $<0.01^{* *}$ \\
\hline Nötrofil & $3,11 \pm 0.3$ & $5,28 \pm 0.6$ & $4,47 \pm 0.2$ & $<0.01^{* *}$ \\
\hline Lenfosit & $0,62 \pm 0.0$ & $1,95 \pm 0.2$ & $2,35 \pm 0.1$ & $<\mathbf{0 . 0 1}$ *** \\
\hline NLR & $7,7 \pm 1,6$ & $4,4 \pm 0.7$ & $3,8 \pm 1,7$ & $<0.01^{* *}$ \\
\hline Hemoglobin & $13,11 \pm 0,2$ & $13,21 \pm 0,2$ & $13,81 \pm 0,3$ & $<0.01^{* *}$ \\
\hline Platelet & $89,58 \pm 7$, & $195 \pm 17$, & $251 \pm 9,7$ & $<\mathbf{0 , 0 1 * * *}$ \\
\hline PLR & $284 \pm 52$ & $160 \pm 24$ & $111,8 \pm 5,7$ & $<0.01^{* *}$ \\
\hline MPV & $8,36 \pm 0.1$ & $7,65 \pm 0.1$ & $7,39 \pm 0.1$ & $<0.01^{* *}$ \\
\hline RDW & $14.7 \pm 0.6$ & $13.6 \pm 0.2$ & $13.6 \pm 0.2$ & $<0.01^{* *}$ \\
\hline
\end{tabular}

Crimean congo hemorrhagic fever and Complete blood parameters Doğan ve ark. 
* İkili grup karşılaştırmaları için Bonferoni düzeltilmesi yapılmıştır ve yeni p değeri 0,016 olarak hesaplanmıştır. ** Aradaki fark pozitif grubundan kaynaklanmaktadır. Kontrol ve negatif gruplar arasında istatistiksel anlamlı fark bulunmamaktadır. *** Fark bütün gruplar arasında istatistiksel olarak anlamlı bulunmuștur. WBC:Lökosit, NLR: Nötrofillenfosit oran1, PLR: Platelet-Lenfosit oranı, MPV: ortalama platelet hacmi, RDW: kırmızı kan hücreleri dağılım genişliği

KKKA pozitif ve negatif gruplar arasında NLO ve PLO için ROC analizi yapılmış ve eğri altında kalan alan (AUC) hesaplanmıştır. Buna göre NLO için AUC değeri 0.67 ve PLO değeri için 0.61 olarak bulunmuştur (Şekil 1).

\section{Tartışma}

KKKA tanılı hastalar ile yaptığımız çalışmamızda; MPV, NLR PLR ve RDW düzeylerini kontrol grubundan yüksek bulduk. Bu yüzden son y1llarda inflamasyon belirteci olarak gösterilen bu tam kan parametrelerinin KKKA hastalarında tanısal etkinliği olabileceğini öngörmekteyiz.

Kene kaynaklı viral hastalıklar arasında en yaygını olan KKKA, ilk kez Eski Sovyetler Birliği'nde ve Kongo'da tanımlanmış daha sonra Avrupa, Asya ve Afrika'ya hızla yayılarak 30'dan fazla ülkede bildirilmiştir (10). KKKA, 2002'den beri Türkiye genelinde şiddeti ve yaygın dağılımı nedeniyle bir halk sağlığı sorunu olmuştur. Bildirilen mortalite \% 5- 30 arasında değişmektedir (11). Öztürk ve arkadaşları (12) mortalite oranını 5.4\%, Baştuğ ve arkadaşları (13) ise $16.4 \%$ olarak vermiştir. Bu oranın Türkiye ortalamasından daha yüksek olmasının sebebini ise; KKKA'li hastaların yoğun bakım tedavisi için hastanelerine sevk edilmesine dayandırmışlardır. Bizim çalışmamızdaki mortalite oranı $12.5 \%$ olup literatürdeki çalışmalarla ile benzerdir.

Ölümcül klinik progresyon gösteren KKKA hastaları özellikle yüksek nötrofil ve düşük lenfosit / monosit sayılarına sahiptir (14). Nötrofillerdeki artış, aşırı sitokin salımına yol açarken, lenfosit ve monositlerdeki azalma, immünite ve humoral antikor yanıtın azalması ile sonuçlanır (13). Bu durum doku ve organlarda, başta mononükleer hücrelerin ve nötrofillerin ağırlıklı olduğu inflamasyona yol açar. Makrofaj ve endotel hücrelerinin aktive olmasıly sistemik inflamatuvar yanıt sendromu (SIRS) ve ölüm gelişir (15). KKKA'de proinflamatuar sitokinlerdeki artış nedeniyle oluşan hemofagositik lenfohistiyositoz, retiküloendotelyal sistem aktivasyonuna ve hemofagositik makrofaj proliferasyon artışına neden olur. Sonuç olarak, lökosit ve trombosit sayıları hızla azalır (16). Trombositopeni, KKKA'nın ana laboratuvar parametrelerinden biridir (17). İnci'nin (18) çalışmasında; lökositlerin ve trombosit değerlerinin KKKA hastalarında kontrol grubundan anlamlı derecede düşük olduğu belirtilmiştir. Başka bir çalışmada, fetal grupta AST, LDH nötrofil, lökositler ve d-dimer anlamlı derecede yüksek iken, trombosit ve fibrinojen seviyeleri anlamlı olarak düşük bulunmuştur (19). Baştuğ ve arkadaşları (13) KKKA'de monosit ve lenfosit miktarlarındaki azalma ve nötrofil sayılarındaki artışının kötü sonuçlarla ilişkili olduğunu belirtmişlerdir. Ayrıca KKKA'li hastaların hayatta kalması için mononükleer immün cevabın önemli olduğunu vurgulamışlardır. Bizim çalışmamızda da hasta grubunun lökosit, lenfosit ve platelet düzeyleri anlamlı derecede düşük bulundu. Bunun sebebi; hastalığın patogenezine bağlı gelişen mekanizmalar, vücutta oluşan immun cevap ve kemik iliğinde meydana gelen değiş̧ikler olarak düşünülmüştür.

Mean Platelet Volume (MPV); tam kan sayımlarından elde edilen, trombosit fonksiyonu ve trombosit aktivasyonu gösteren; maliyeti düşük ve invazif olmayan bir belirteçtir (20). Son yıllarda yapılan çalışmalarda, MPV'nininflamasyonbelirteciolarak kullanılabileceğine dair sonuçlar bildirilmiştir. Literatürde kardiyovasküler hastalıklar, periferal arter hastalıkları ve serebrovasküler olaylar, otoimmün hastalıklar ve viral hepatit enfeksiyonlarında MPV seviyelerinin $\operatorname{arttığı~gösterilmiştir~(21).~Yapılan~bir~çalışmada,~KKKA'lı~hastalarda~}$ MPV düzeylerinin kontrol grubundakilere göre daha yüksek olduğu bildirilmiştir.Ayrıca MPV'nin hem hastane yatış süresi hem de mortalite için bir belirleyici olduğu bulunmuştur (22). Ertürk ve arkadaşları (16) ise çalışmalarında; KKKA'li hastalardaki hemofagositozun aşırı pro-inflamatuar sitokinler nedeniyle ortaya çıtıtı̆ııı, genç ve aktif trombositler perifere salınırken lökosit ve trombosit sayılarının hızlı bir şekilde azalıp MPV seviyelerinin arttığını söylemiştir. Fakat, MPV seviyelerinin hastane yatı̧s süresini değerlendirmek için yeterli olmadığını belirtmişlerdir. Bizim çalışmamızdaki MPV düzeylerinin yüksekliği de hastalığın inflamatuar sürecindeki pro-inflamatuar sitokinlerin artışına sekonder trombositlerin kemik iliğinden kana salınımına dayandırılabilir.

Nötrofil/lenfosit oranı (NLR) ve trombosit-lenfosit oranı (PLR); yine tam kan sayımlarından kolaylıkla elde edilen düşük maliyetli ve invazif olmayan birer inflamasyon belirtecidir $(23,24)$. Yapılan çalışmalarda; kronik inflamatuar hastalıklar, maligniteler, enfeksiyonlar, renal ve hepatik yetmezlikler, tiroid hastalıkları gibi durumlarda NLR'nin etkilendiği gösterilmiştir (25). Aynı şekilde son yıllarda, çeşitli hastalıkların tanı ve prognozunda PLR'nin etkinliğini de değerlendiren çalışmaların sayısı gittikçe artmıştır (14). PLR inflamasyonu gösteren yeni bir biyomarkerdir (26). PLR, periferik arteriyel hastalıklarda kötü prognoz ile ilişkilidir (27). Ayrıca, PLR'nin birçok malignitede prognostik faktör olduğu düşünülmektedir (28). NLR ve PLR, Behçet Syndrome'nin varlığı ve şiddeti ile ilişkili olabilir (23). Cho ve ark. (29) ilaç salınımlı stent ile perkütan koroner girişim geçirmiş olan hastalarda PLR ve NLR'yi analiz ettiği çalışmasında; özellikle PLR ve NLR'nin kombine edildiğinde bu hastalarda uzun süreli olumsuz klinik sonuçların bağımsız tahmincileri olduğunu vurgulamışlardır.

Yüksek sensitivite ve spesifisiteye sahip olan PLR, özellikle acil servislerde KKKA da mortalite oranını ve kan ürünü transfüzyonu ihtiyacını önceden tahmin edebilen basit bir skorlama sistemi olabilir (14). Ertürk ve arkadaşları (16) KKKA'lı hasta grubunun NLR ve PLR'sinin kontrol grubuna benzediğini bulmuştur. Türkdoğan ve arkadaşları (19) çalışmalarında, KKKA'li hastalarda NLR'nin önemli ölçüde düşük ve bu düşüklüğün de hastalık şiddeti ile güçlü bir şekilde ilişkili olduğunu belirtmişlerdir. Yapılan çalışmalar ve çalışmamızda elde edilen sonuçlara göre; KKKA'lı hastalarda NLR ve PLR'nin inflamatuar süreçten etkilenen, tanı, tedavi ve hastane yatış süresince faydalanılabilecek belirteçler olduğu düşünülebilir.

Kırmızı hücre dağılım genişliği (RDW) hücre boyutlarında daha büyük heterojenite yansıtan yüksek değerler ile dolaşan eritrositlerin boyutlarındaki değişikliğin kantitatif bir ölçümüdür (ie, anisocytosis). RDW kolay, ucuz ve tam kan testinde rutin olarak bak1labilen bir parametredir (30). RDW düzeylerindeki artışın altında yatan kesin mekanizma henüz tanımlanmamıştır; Ancak, akut veya kronik iltihaplanma ile eritrosit deformasyonu olabileceği bildirilmiştir (31). Günümüzde birçok çalışmada artmış RDW düzeyleri çölyak hastalığı, pulmoner emboli, koroner arter hastalığı, şiddetli sepsis ve septik şok gibi inflamatuar hadiseler ile ilişsili bulunmuştur. (32-34) . Biz literatürde KKKA hastalarında RDW ile ilgili yapılmış bir çalışmaya rastlamadık. Bizim çalışmamızda RDW düzeyleri bu hasta grubunda yüksek bulunmuştur. Ancak KKKA ve RDW ilişkisinden bahsetmek 
için yapılacak daha fazla sayıda çalışmaya ihtiyaç vardır.

\section{Limitasyonlar}

Çalışmadaki ex olan hasta sayısı yetersiz olduğu için araştırılan tam kan parametrelerinin mortalite üzerine olan etkisi değerlendirilememiştir. Bazı hastaların hastanemizdeki takibi esnasında başka bir üst seviye hastaneye nakli gerçekleştiği için hastane yatış süreleri ve bu parametrelerin bu süreler üzerine olan etkisi de net olarak incelenememiştir. Aynı zamanda çalışma retrospektif olduğundan bu tam kan belirteçlerinin tedavi süresi içindeki değişimleri de takip edilememiştir.

\section{Sonuç}

KKKA tanılı hastalarda MPV, NLR, PLR ve RDW düzeyleri kontrol grubuna göre yüksek bulunmuştur. $\mathrm{Bu}$ çalışmada elde edilen verilere göre özellikle acil servislerde ucuz, kolay ve yaygın olarak kullanılabilecek bu tam kan parametreleri KKKA tanısında klinisyenlere yardımcı olabilir. Bu parametreler ile ilgili yapılacak daha kapsamlı çalışmalara ihtiyaç vardır.

\section{Kaynaklar}

1. Whitehouse, C.A. Crimean-Congo hemorrhagic fever. Antiviral Res. 2004:64;145160

2. Ergönül Ö. Kırım Kongo kanamalı ateşi tedavisi ve ribavirin kullanımı. Klimik Dergisi. 2016;29:2-9

3. Burt F.J, Swanepoel R, Shieh W.J, et al. Immunohistochemical and in situ localization of Crimean-Congo hemorrhagic fever (CCHF) virus in human tissues and implications for CCHF pathogenesis. Arch. Pathol. Lab. Med. 1997: 121; 839 846 .

4. Feldmann H, Jones S, Klenk H.D, Schnittler H.J. Ebola virus: From discovery to vaccine. Nat. Rev. Immunol. 2003: 3; 677-685.

5. Öngürü P, Bodur H. Crimean-congo haemorrhagic fever. J. Exp. Clin. Med. 2012; 29: S175-S181

6. Sonmez O, Ertas G, Bacaksız A, Tasal A, Erdogan E, Asoglu E. Relation of neutrophil-to-lymphocyte ratio with the presence and complexity of coronary artery disease. An observational study. Anadolu Kardiyol Derg. 2013;13:662e7

7. Yazici S, Yazici M, Erer B, Erer B, Calik Y, Bulur S. The platelet functions in patients with ankylosing spondylitis, antiTNF-alpha therapy decreases the mean platelet volume and platelet mass. Platelets 2010;21:126e31.

8. Azab B, Shah N, Akerman M, McGinn Jr JT. Value of platelet/lymphocyte ratio as a predictor of all-cause mortality after non-ST elevation myocardial infarction. J Thromb Thrombolysis 2012;34:326e34

9. Ertekin B, Kara H, Erdemir E, Doğan E, Acar T, Demir L.S. Efficacy of Use of Red Cell Distribution Width as a Diagnostic Marker in Acute Appendicitis. Eurasian J Emerg Med 2017; 16: 29-33

10. Uyar Y, Christova I, Papa A. Current situation of Crimean Congo hemorrhagic fever (CCHF) in Anatolia and Balkan Peninsula. Türk Hijyen ve Deneysel Biyoloji Dergisi 2011; 68: 139 - 151

11. Yilmaz GR, Buzgan T, Irmak H. The epidemiology of Crimean-Congo hemorrhagic fever in Turkey, 2002-2007. Int J Infect Dis 2009;13:380-6.

12. Ozkurt Z, Kiki I, Erol S et al. Crimean-Congo hemorrhagic fever in Eastern Turkey: clinical features, risk factors and efficacy of ribavirin therapy. J Infect 2006: 52; 207-215.

13. Bastug A, Kayaaslan B, Kazancioglu S, et al. Crimean-Congo hemorrhagic fever: Prognostic factors and the association of leukocyte counts with mortality. Jpn J Infect Dis 2016: 69; 51-55

14. Eren S. H, Zengin S, Büyüktuna S.A, Gözel M.G. Clinical severity in forecasting platelet to lymphocyte ratio in Crimean-Congo hemorrhagic fever patients. J Med Microbiol 2016: 65;1100-1104

15. Akıncı E, Bodur H, Leblebicioglu H. Pathogenesis of Crimean-Congo hemorrhagic fever. Vector Borne Zoonotic Dis 2013;13: 429-437.

16. Ertürk A, Cüre E, Parlak E, Cüre M.C. Yüce S, Özkurt Z. Prognostic value of mean platelet volume and neutrophil to lymphocyte ratio in patients with CrimeanCongo Hemorrhagic Fever. JMID 2015;5:51-56

17. Vorou R, Pierroutsakos I. N. Maltezou H. C. CrimeanCongo hemorrhagic fever. Curr Opin Infect Dis. 2007; 20: 495-500.

18. Inci A. Increased Mean Platelet Volume in Patients with Crimean Congo Hemorrhagic Fever. J Clin Anal Med 2015;6:1-3.

19. Turkdogan K.A, Eren S.H, Coskun A, Engin A, Sonmez E, Civelek C. Ratio of neutrophil to lymphocyte Counts in Crimean Congo Hemorrhagic Fever. J Clin

Genel Tip Derg 2021;31(2)101-104

104
Anal Med 2016;7: 10-3

20. Gasparyan AY, Ayvazyan L, Mikhailidis DP, Kitas GD. Mean platelet volume: a link between thrombosis and inflammation? Curr Pharm Des 2011;17:47-58

21. Beyan C. Is mean platelet volume a predictive marker in patients with venous thrombosis? Clin Appl Thromb Hemost 2012;18:670-1.

22. Ekiz F, Gürbüz Y, Basar Ö, et al. Mean platelet volume in the diagnosis and prognosis of Crimean-Congo hemorrhagic fever. Clin Appl Thromb Hemost 2013;19:441-4.

23. Alan S, Tuna S, Turkoğlu E.B. The relation of neutrophil-to-lymphocyte ratio, platelet-to-lymphocyte ratio, and mean platelet volume with the presence and severity of Behcet's syndrome. Kaohsiung J Med Sci 2015; 31: 626-631

24. Harmanci O, Kav T, Sivri B. Red cell distribution width can predict intestinal atrophy in selected patients with celiac disease. J Clin Anal Med 2012;26:497-502

25. Tanoglu A, Karagoz E, Ulcay A, Turhan V, Kara M, Yazgan Yusuf. Clinica Significance of Neutrophil to Lymphocyte Ratio and Mean Platelet Volume for Predicting the Severity of Hepatic Fibrosis in Patients with Chronic Hepatitis B. Medicine Science 2016;5:147-59

26. Koseoglu HI, Altunkas F, Doruk S, Etikan I, Demir O, Kanbay A. Plateletelymphocyte ratio is an independent predictor for cardiovascular disease in obstructive sleep apnea syndrome. J Thromb Thrombolysis 2015;39:179e85

27. Macey M, Hagi-Pavli E, Stewart J, et al. Age, gender and disease related platelet and neutrophil activation ex vivo in whole blood samples from patients with Behcet's disease. Rheumatology 2011;50: 1849-59.

28. Proctor MJ, Morrison DS, Talwar D, et al. A comparison of inflammation-based prognostic scores in patients with cancer. A Glasgow Inflammation Outcome Study. Eur J Cancer 2011;47:2633-41.

29. Cho K.I, Ann S.H, Singh G.B, Her A.Y, Shin E.S. Combined usefulness of the platelet-to-lymphocyte ratio and the neutrophil-to-lymphocyte ratio in predicting the long-term adverse events in patients who have undergone percutaneous coronary intervention with a drug-eluting stent. PLoS One 2015: Jul 24;10:e0133934.

30. Sadaka F, O'Brien J, Prakash S. Red Cell Distribution Width and Outcome in Patients With Septic Shock. J Intensive Care Med. 2013;28:307-13.

31. Senol K, Saylam B, Kocaay F, Tez M. Red cell distribution width as a predictor of mortality in acute pancreatitis. Am J Emerg Med 2013; 31: 687-9.

32. Hampole CV, Mehrotra AK, Thenappan T, Gomberg-Maitland M, Shah SJ. Usefulness of red cell distribution width as a prognostic marker in pulmonary hypertension. Am J Cardiol 2009; 104: 868-72

33. Tonelli M, Sacks F, Arnold M, Moye L, Davis B, Pfeffer M; for the Cholesterol and Recurrent Events (CARE) Trial Investigators: Relation Between Red Blood Cell Distribution Width and Cardiovascular Event Rate in People With Coronary Disease. Circulation 2008; 117: 163-68

34. Ku NS, Kim HW, Oh HJ, et al. Red blood cell distribution width is an independent predictor of mortality in patients with gram-negative bacteremia. Shock 2012;38: $123-27$
Crimean congo hemorrhagic fever and Complete blood parameters Doğan ve ark. 